\title{
Adding Biotin to Parenteral Nutrition Solutions Without Lipid Accelerates the Growth of Candida albicans
}

\author{
Takashi Kuwahara $^{凶}$, Shinya Kaneda, Kazuyuki Shimono \\ Naruto Research Institute, Research and Development Center, Otsuka Pharmaceutical Factory, Inc., 115 Tateiwa, Naruto, Tokushima 772-8601, Japan. \\ $\triangle$ Corresponding author: Takashi Kuwahara, Ph.D. Naruto Research Institute, Research and Development Center, Otsuka Pharmaceutical Factory, Inc., 115 \\ Tateiwa, Naruto, Tokushima 772-8601, Japan. \\ (c) Ivyspring International Publisher. Reproduction is permitted for personal, noncommercial use, provided that the article is in whole, unmodified, and properly cited. See \\ http://ivyspring.com/terms for terms and conditions.
}

Received: 2016.04.25; Accepted: 2016.08.22; Published: 2016.09.15

\begin{abstract}
Background: We have previously demonstrated that Candida albicans requires multivitamins (MVs) or lipid to increase rapidly in parenteral nutrition (PN) solutions. In this study, in detail, the effects of vitamins on the growth of $C$. albicans in PN solutions without lipid were investigated. Methods: In the 1st experiment, a commercial PN solution without lipid was supplemented with water-soluble vitamins (SVs: vitamins $B_{1}, B_{2}, B_{6}, B_{12}$ and $C$, folic acid, nicotinamide, biotin and panthenol), water-insoluble vitamins (IVs: vitamins A, D, E and K) or both (MVs). In the 2nd experiment, the test solutions were prepared by supplementing the PN solution with one of each or all of the SVs. In the 3rd experiment, another commercial peripheral PN (PPN) solution without lipid was supplemented with SVs, nicotinic acid, biotin or both nicotinic acid and biotin. In each of the experiments, a specified number of $C$. albicans organisms was added to each test solution, and all of the test solutions were allowed to stand at room temperature $\left(23-26^{\circ} \mathrm{C}\right)$. The number of $C$. albicans was counted at 0, 24, 48 and 72 hours after the addition of the organism. Results: In the Ist experiment, the $C$. albicans increased rapidly in the PN solution supplemented with the SVs, but increased slowly without the SVs, regardless of the addition of the IVs. In the 2nd experiment, the C. albicans increased rapidly in the PN solution supplemented with the SVs or biotin, but increased slowly with each of the other water-soluble vitamins. In the $3 r$ d experiment, the $C$. albicans increased rapidly in the PPN solution supplemented with the SVs or biotin, but increased slowly with the addition of nicotinic acid. Conclusions: These results suggested that adding MVs or SVs to $\mathrm{PN}$ solutions without lipid promotes the growth of $C$. albicans, and that this effect is mostly attributable to biotin.
\end{abstract}

Key words: Candida albicans, microbial growth, parenteral nutrition, biotin, vitamin, blood stream infection.

\section{Introduction}

A catheter-related blood stream infection (CRBSI) is one of the most common complications of intravenous catheters [1-5]. In order to reduce or prevent CRBSIs, factors that enhance or inhibit microbial growth in parenteral solutions should be investigated and identified. With regard to microorganisms, Staphylococcus aureus, coagulase-negative staphylococci, Candida albicans, Escherichia coli, Klebsiella pneumonia, etc. have been shown as the major contributors to CRBSIs in patients receiving parenteral nutrition $(\mathrm{PN})[2,3,6]$. Among these causative microorganisms, only $C$. albicans can grow in acidic PN solutions [7-11], such as those with a $\mathrm{pH}$ of 4.5 [12], and $C$. albicans causes higher mortality and morbidity than the bacterial species [13-17]. We have previously demonstrated that $C$. albicans increased slightly in a peripheral parenteral nutrition (PPN) solution consisting of amino acids, carbohydrates and electrolytes, and increased rapidly in the same PPN solution with a lipid emulsion or 
multivitamins (MVs) [18]. We have also shown that adding MVs to PN solutions without lipid promoted the growth of $C$. albicans, but adding trace elements had no effect on the growth [19].

In the present study, the effects of vitamins on the growth of C. albicans in PN solutions without lipid were investigated in detail. First, we examined the growth of $C$. albicans in a PN solution without lipid supplemented with water-soluble vitamins (SVs), water-insoluble vitamins (IVs) or both (MVs). Additionally, in order to identify which specific vitamin(s) enhanced the growth of $C$. albicans, we supplemented the PN solution with individual SVs.

\section{Materials and Methods}

\section{Microorganisms employed}

A standard American Type Culture Collection strain (ATCC10231) and 2 clinical isolates (N-6 and $\mathrm{N}-8$ ) of Candida albicans were used in the 1st experiment. The N-6 and N-8 clinical isolates were used in the 2nd experiment, and N-6 was used in the 3rd experiment.

\section{Test solutions}

A commercial PN solution (without lipid) for central venous nutrition (AMINOTRIPA No.1, Otsuka Pharmaceutical Factory, Inc., Japan) was used as the control PN solution (CPN) in the 1st and 2nd experiments. An additional commercial PN solution for peripheral venous nutrition (AMINOFLUID, Otsuka Pharmaceutical Factory, Inc.) was used as the control PPN solution (CPPN) in the 3rd experiment. A commercial multivitamin preparation (Otsuka MV Injection, Otsuka Pharmaceutical Factory, Inc.) was used for the MVs, and consisted of a vial containing SVs (vitamins $B_{1}, B_{2}, B_{6}, B_{12}$ and $C$, folic acid, nicotinamide, biotin and panthenol) and an ampule containing IVs (vitamins A, D, E and K). The compositions of the CPN, CPPN and MVs are shown in Tables 1, 2 and 3, respectively.

In the 1st experiment, 3 test solutions (PN+SVs, $\mathrm{PN}+\mathrm{IVs}$ and $\mathrm{PN}+\mathrm{MVs}$ ) were prepared by supplementing one bag $(850 \mathrm{~mL}$; one-half of the daily dose) of CPN with a daily dose of SVs, IVs or MVs.

Table 1. Composition of CPN (AMINOTRIPA No.1).

\begin{tabular}{llll}
\hline \multicolumn{4}{c}{ Composition per $850 \mathrm{~mL}$ (one-half of the daily dose) } \\
\hline L-Leucine & $3.500 \mathrm{~g}$ & Total amino acids & $25.0 \mathrm{~g}$ \\
L-Isoleucine & $2.000 \mathrm{~g}$ & Glucose & $79.8 \mathrm{~g}$ \\
L-Valine & $2.000 \mathrm{~g}$ & Fructose & $40.2 \mathrm{~g}$ \\
L-Lysine Acetate & $3.700 \mathrm{~g}$ & Xylitol & $19.8 \mathrm{~g}$ \\
(as L-Lysine) & $(2.625 \mathrm{~g})$ & & \\
L-Threonine & $1.425 \mathrm{~g}$ & $\mathrm{Na}^{+}$ & $35 \mathrm{mEq}$ \\
L-Tryptophan & $0.500 \mathrm{~g}$ & $\mathrm{~K}^{+}$ & $22 \mathrm{mEq}$ \\
L-Methionine & $0.975 \mathrm{~g}$ & $\mathrm{Mg}^{2+}$ & $4 \mathrm{mEq}$ \\
L-Cysteine & $0.250 \mathrm{~g}$ & $\mathrm{Ca}^{2+}$ & $4 \mathrm{mEq}$ \\
L-Phenylalanine & $1.750 \mathrm{~g}$ & $\mathrm{Cl}^{-}$ & $35 \mathrm{mEq}$ \\
L-Tyrosine & $0.125 \mathrm{~g}$ & SO$^{2-}$ & $4 \mathrm{mEq}$ \\
L-Arginine & $2.625 \mathrm{~g}$ & $\mathrm{Acetate}^{-*}$ & $44 \mathrm{mEq}$ \\
L-Histidine & $1.250 \mathrm{~g}$ & $\mathrm{Gluconate}^{-}$ & $4 \mathrm{mEq}$ \\
L-Alanine & $2.000 \mathrm{~g}$ & $\mathrm{Citrate}^{3-}$ & $10 \mathrm{mEq}$ \\
L-Proline & $1.250 \mathrm{~g}$ & $\mathrm{P}$ & $5 \mathrm{mmol}$ \\
L-Serine & $0.750 \mathrm{~g}$ & Zn & $8 \mu \mathrm{mol}$ \\
Glycine & $1.475 \mathrm{~g}$ & & Characteristics \\
L-Aspartic acid & $0.250 \mathrm{~g}$ & pH & 5.6 \\
L-Glutamic acid & $0.250 \mathrm{~g}$ & OPR & Approximately 5 \\
\hline *, including the amount derived from the additives. & \\
OPR, osmotic pressure ratio to physiological saline. &
\end{tabular}

Table 2. Composition of CPPN (AMINOFLUID).

\begin{tabular}{|c|c|c|c|}
\hline \multicolumn{4}{|c|}{ Composition per $1000 \mathrm{~mL}$ (one-half of the daily dose) } \\
\hline L-Leucine & $4.200 \mathrm{~g}$ & Total amino acids & $30.00 \mathrm{~g}$ \\
\hline L-Isoleucine & $2.400 \mathrm{~g}$ & Glucose & $75.00 \mathrm{~g}$ \\
\hline L-Valine & $2.400 \mathrm{~g}$ & & \\
\hline L-Lysine $\mathrm{HCl}$ & $3.930 \mathrm{~g}$ & $\mathrm{Na}^{+}$ & $35 \mathrm{mEq}$ \\
\hline (as L-Lysine) & $(3.146 \mathrm{~g})$ & $\mathrm{K}^{+}$ & $20 \mathrm{mEq}$ \\
\hline L-Threonine & $1.710 \mathrm{~g}$ & $\mathrm{Mg}^{2+}$ & $5 \mathrm{mEq}$ \\
\hline L-Tryptophan & $0.600 \mathrm{~g}$ & $\mathrm{Ca}^{2+}$ & $5 \mathrm{mEq}$ \\
\hline L-Methionine & $1.170 \mathrm{~g}$ & $\mathrm{Cl}^{-}$ & $35 \mathrm{mEq}$ \\
\hline L-Cysteine & $0.300 \mathrm{~g}$ & $\mathrm{SO}_{4}^{2-}$ & $5 \mathrm{mEq}$ \\
\hline L-Phenylalanine & $2.100 \mathrm{~g}$ & Acetate $^{-*}$ & $13 \mathrm{mEq}$ \\
\hline L-Tyrosine & $0.150 \mathrm{~g}$ & Gluconate- & $5 \mathrm{mEq}$ \\
\hline L-Arginine & $3.150 \mathrm{~g}$ & L-Lactate- & $20 \mathrm{mEq}$ \\
\hline L-Histidine & $1.500 \mathrm{~g}$ & Citrate $^{3-*}$ & $6 \mathrm{mEq}$ \\
\hline L-Alanine & $2.400 \mathrm{~g}$ & $\mathrm{P}$ & $10 \mathrm{mmol}$ \\
\hline L-Proline & $1.500 \mathrm{~g}$ & $\mathrm{Zn}$ & $5 \mu \mathrm{mol}$ \\
\hline L-Serine & $0.900 \mathrm{~g}$ & & \\
\hline Glycine & $1.770 \mathrm{~g}$ & Cha & istics \\
\hline L-Aspartic acid & $0.300 \mathrm{~g}$ & $\mathrm{pH}$ & 6.6 \\
\hline L-Glutamic acid & $0.300 \mathrm{~g}$ & OPR & Approximately 3 \\
\hline
\end{tabular}

Table 3. Composition of MVs (Otsuka MV Injection).

\begin{tabular}{ll}
\hline \multicolumn{2}{c}{ Composition per $4 \mathrm{~mL}$ (a daily dose) } \\
\hline SVs (Water-soluble vitamins) & $3.1 \mathrm{mg}$ \\
Vitamin $\mathrm{B}_{1}$ & $3.6 \mathrm{mg}$ \\
Vitamin $\mathrm{B}_{2}$ & $4.0 \mathrm{mg}$ \\
Vitamin $\mathrm{B}_{6}$ & $0.005 \mathrm{mg}$ \\
Vitamin $\mathrm{B}_{12}$ & $100 \mathrm{mg}$ \\
Vitamin C & $0.4 \mathrm{mg}$ \\
Folic acid & $40 \mathrm{mg}$ \\
Nicotinamide & $0.06 \mathrm{mg}$ \\
Biotin & $14 \mathrm{mg}$ \\
Panthenol & \\
IVs (Water-insoluble vitamins) & $3300 \mathrm{Vit} . \mathrm{A} \mathrm{IU}$ \\
Vitamin A oil & $0.005 \mathrm{mg}$ \\
Vitamin $\mathrm{D}_{3}$ & $10 \mathrm{mg}$ \\
Vitamin E & $2 \mathrm{mg}$ \\
Vitamin K &
\end{tabular}

Vit.A IU, international unit for vitamin A. 
In the 2nd experiment, the test solutions $(\mathrm{PN}+\mathrm{B} 1$, $\mathrm{PN}+\mathrm{B} 2, \mathrm{PN}+\mathrm{B} 6, \quad \mathrm{PN}+\mathrm{B} 12, \mathrm{PN}+\mathrm{C}, \mathrm{PN}+$ Folic acid, $\mathrm{PN}+$ Nicotinic acid, $\mathrm{PN}+$ Biotin and $\mathrm{PN}+$ Panthenol) were prepared by supplementing each $100 \mathrm{~mL}$ of CPN in a sterile screw-capped plastic flask (polycarbonate Erlenmeyer flask, $125 \mathrm{~mL}$; Corning Inc., MA, US) with each water-soluble vitamin. To prepare the PN+B1, $100 \mu \mathrm{L}$ of a commercial vitamin $\mathrm{B}_{1}$ injection (Thiamine hydrochloride, $10 \mathrm{mg} / \mathrm{mL}$; NIPRO Pharma Co., Japan) was added to the CPN, resulting in 0.01 $\mathrm{mg} / \mathrm{mL}$ of thiamine hydrochloride. To prepare the $\mathrm{PN}+\mathrm{B} 2,100 \mu \mathrm{L}$ of a commercial vitamin $\mathrm{B}_{2}$ injection (Bisulase, $10 \mathrm{mg} / \mathrm{mL}$; TOA EIYO Ltd., Japan) was added to the $\mathrm{CPN}$, resulting in $0.01 \mathrm{mg} / \mathrm{mL}$ of riboflavin sodium phosphate. The $\mathrm{PN}+\mathrm{B} 6$ was prepared by adding $100 \mu \mathrm{L}$ of a commercial vitamin $\mathrm{B}_{6}$ injection (Pydoxal, $30 \mathrm{mg} / \mathrm{mL}$; CHUGAI Pharmaceutical Co., Ltd., Japan) to the CPN, resulting in $0.03 \mathrm{mg} / \mathrm{mL}$ of pyridoxal phosphate. To prepare the $\mathrm{PN}+\mathrm{B} 12,100 \mu \mathrm{L}$ of a commercial vitamin $\mathrm{B}_{12}$ injection (Hitocovamine $\mathrm{M}, 500 \mu \mathrm{g} / \mathrm{mL}$; NIPRO Pharma Co.) was added to the CPN, resulting in 0.5 $\mu \mathrm{g} / \mathrm{mL}$ of mecobalamin. The $\mathrm{PN}+\mathrm{C}$ was prepared by adding $100 \mu \mathrm{L}$ of a commercial vitamin $\mathrm{C}$ injection (Vitacimin, $100 \mathrm{mg} / \mathrm{mL}$; Takeda Pharmaceutical Company Ltd., Japan) to the CPN, resulting in 0.1 $\mathrm{mg} / \mathrm{mL}$ of ascorbic acid. To prepare PN+Folic acid, $100 \mu \mathrm{L}$ of a commercial folic acid injection (Foliamin; $15 \mathrm{mg} / \mathrm{mL}$; Nihon Pharmaceutical Co., Ltd., Japan) was added to the CPN, resulting in $0.015 \mathrm{mg} / \mathrm{mL}$ of folic acid. The PN+Nicotinic acid was prepared by adding $200 \mu \mathrm{L}$ of a commercial nicotinic acid injection (Nyclin, $20 \mathrm{mg} / \mathrm{mL}$, TOA EIYO Ltd.) to the CPN, resulting in $0.04 \mathrm{mg} / \mathrm{mL}$ of nicotinic acid. To prepare the PN+Biotin, $200 \mu \mathrm{L}$ of a commercial biotin injection (Biotin, $1 \mathrm{mg} / 2 \mathrm{~mL}$; FUSO Pharmaceutical Industries, Ltd., Japan) was added to the CPN, resulting in 0.001 $\mathrm{mg} / \mathrm{mL}$ of biotin. The PN+Panthenol was prepared by adding $100 \mu \mathrm{L}$ of a commercial panthenol injection (Pantol, $100 \mathrm{mg} / \mathrm{mL}$; TOA EIYO Ltd.) to the CPN, resulting in $0.1 \mathrm{mg} / \mathrm{mL}$ of panthenol. Finally, the $\mathrm{PN}+\mathrm{SV}$ s was prepared in a similar way to that described above.

In the 3rd experiment, the test solutions (PPN+SVs, PPN+Nicotinic acid, PPN+Biotin and PPN+Nicotinic acid+Biotin) were prepared by supplementing each $100 \mathrm{~mL}$ of CPPN in a flask with $1 / 10$ of the daily dose of the SVs, $0.04 \mathrm{mg} / \mathrm{mL}$ of nicotinic acid, $0.001 \mathrm{mg} / \mathrm{mL}$ of biotin, and both nicotinic acid and biotin $(0.04 \mathrm{mg} / \mathrm{mL}$ and 0.001 $\mathrm{mg} / \mathrm{mL}$, respectively).

\section{Addition of microorganisms, incubation and sampling}

In the 1st experiment, one loopful of organisms from each strain was suspended and diluted to approximately 200 colony forming units (CFU)/mL with physiological saline (Otsuka Normal Saline; Otsuka pharmaceutical Factory, Inc.). One millilitre of the suspension was injected into each bag of test solution, and all of the bags were hung for 72 hours at room temperature $\left(23-26^{\circ} \mathrm{C}\right)$. One aliquot $(3-120 \mathrm{~mL})$ of the test solution was sampled from each bag at 0 , 24, 48 and 72 hours after the addition of the organism.

In the 2nd and 3rd experiments, similar to the procedure described above, the suspensions of $C$. albicans were prepared to achieve approximately 100 $\mathrm{CFU} / \mathrm{mL}$. One millilitre of the suspension was added to each flask of test solution, and all of the flasks were allowed to stand at room temperature $\left(23-26^{\circ} \mathrm{C}\right)$. An aliquot (3-25 $\mathrm{mL}$ ) of each test solution was sampled at $0,24,48$ and 72 hours after the addition of the organism. The values obtained at 0 hours showed the number of $C$. albicans organisms added.

\section{Measurement of viable microorganisms}

Each aliquot of the test solution sampled was inoculated on a Soybean Casein Digest (SCD) agar plate in duplicate. When necessary, the test solution sampled was diluted 10 -fold to $10^{4}$-fold with physiological saline before inoculation. When 1 to 50 $\mathrm{mL}$ of the test solution was examined, the solution was filtered with a membrane filter $(0.45 \mu \mathrm{m}$, nitrocellulose) for the sterility test described by Japanese Pharmacopeia [20], and the filter was put on an SCD agar plate. After 20 to 30 hours of incubation at $37 \pm 1^{\circ} \mathrm{C}$, the number of $C$. albicans CFUs on each plate was counted, and the mean number of the duplicated data was calculated. The number of CFUs per $\mathrm{mL}$ was calculated by using the number of CFUs per plate, the volume inoculated and the dilution ratio. The results were shown as $\mathrm{CFU} / \mathrm{mL}$ values in semi-logarithmic graphs.

As in other experimental studies of microbial growth $[8,21-24]$, the data obtained in this study were not analysed statistically, because the biological significance of this kind of data is considered to be assessable without a statistical analysis.

\section{Results}

\section{First experiment (Figure 1)}

Throughout the time period, both the clinical isolates (N-6 and $\mathrm{N}-8)$ and the standard strain (ATCC10231) of C. albicans increased a little in the $\mathrm{CPN}$, and slowly in the PN+IVs. In the PN+SVs and $\mathrm{PN}+\mathrm{MVs}$, all 3 strains increased a little at 24 hours (as in the CPN), and increased rapidly at 48 hours and 72 hours. The SVs accelerated the growth of $C$. albicans in a way similar to the MVs, but the IVs had little or no effect on the growth. 


\section{Second experiment (Figure 2)}

In the first 24 hours, the N-6 and N-8 clinical isolates increased in a similar way in all of the test solutions. Afterward, the growth of both strains stalled in the $\mathrm{PN}+\mathrm{B} 1, \mathrm{PN}+\mathrm{B} 2, \mathrm{PN}+\mathrm{B} 6, \mathrm{PN}+\mathrm{B} 12, \mathrm{PN}+\mathrm{C}$, $\mathrm{PN}+$ Folic acid and PN+Panthenol (as in the CPN), although the growth increased slowly in the $\mathrm{PN}+$ Nicotinic acid. On the other hand, both strains increased rapidly in the $\mathrm{PN}+\mathrm{Biotin}$ (as in the $\mathrm{PN}+\mathrm{SVs}$ ). Specifically, vitamins $\mathrm{B}_{1}, \mathrm{~B}_{2}, \mathrm{~B}_{6}, \mathrm{~B}_{12}$ and $\mathrm{C}$, and the folic acid and panthenol had no effects on the growth of the C. albicans, while the biotin acted mainly as a promoting factor among the SVs.

\section{Third experiment (Figure 3)}

The N-6 clinical isolate increased slowly in the PPN+Nicotinic acid (as in the CPPN), while it increased rapidly in the PPN+Biotin, PPN+Nicotinic acid +Biotin and PPN+SVs equally. It was confirmed that the biotin acted mostly as a promoting factor among the SVs, but the nicotinic acid did not.

\section{Candida albicans}
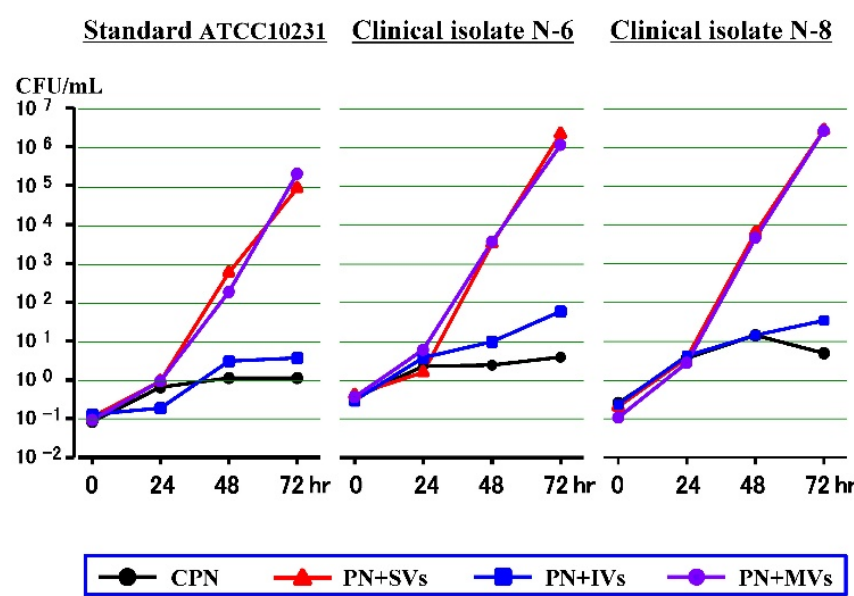

Figure 1. Effects of water-soluble vitamins (SVs), water-insoluble vitamins (IVs) or both (MVs) on the growth of Candida albicans in a PN solution without lipid (CPN).

\section{Candida albicans}

\section{Clinical isolate N-6}

$\mathrm{CFU} / \mathrm{mL}$

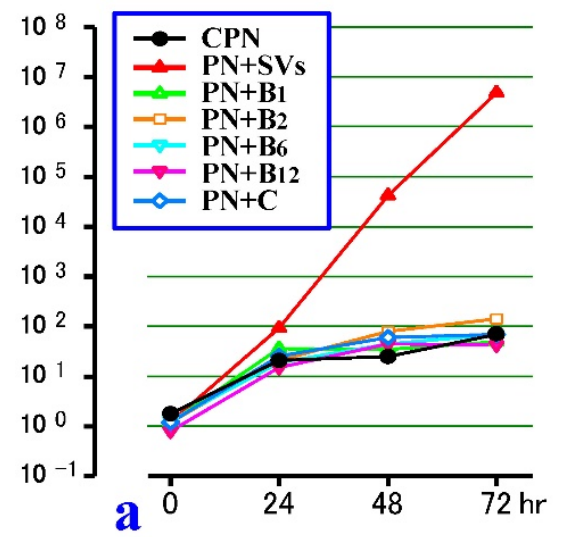

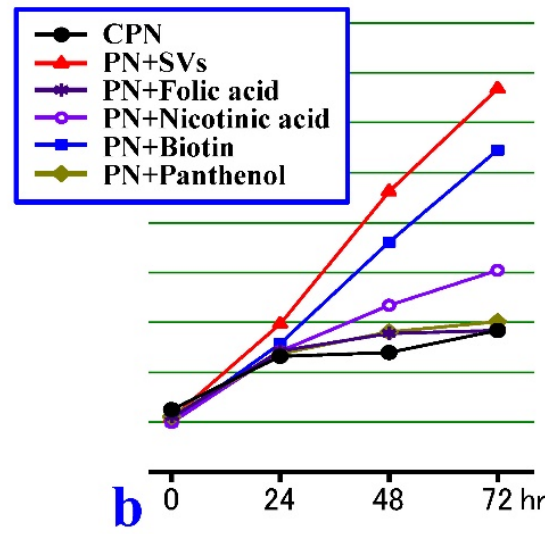

Clinical isolate $\mathrm{N}-8$

CFU $/ \mathrm{mL}$

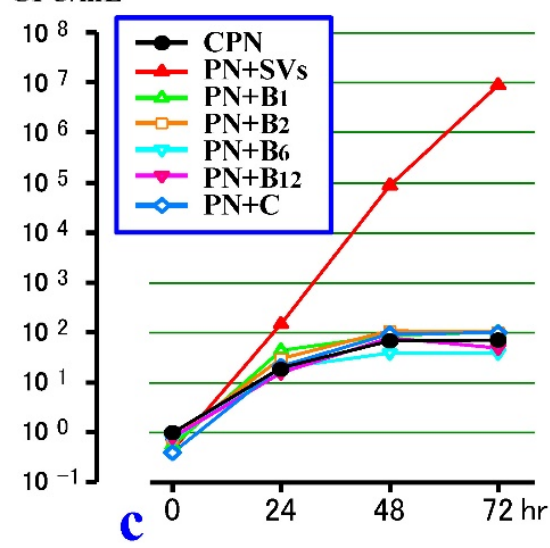

Figure 2. Effects of 9 individual water-soluble vitamins (SVs) on the growth of Candida albicans in a PN solution without lipid (CPN). a. The effects of vitamins B1, B2, B6, B12 or C on the growth of the N-6 clinical isolate. b. The effects of folic acid, nicotinic acid, biotin or panthenol on the growth of N-6. c. The effects of vitamins B1, B2, B6, B12 or C on the growth of the N-8 clinical isolate. d. The effects of folic acid, nicotinic acid, biotin or panthenol on the growth of N-8. 


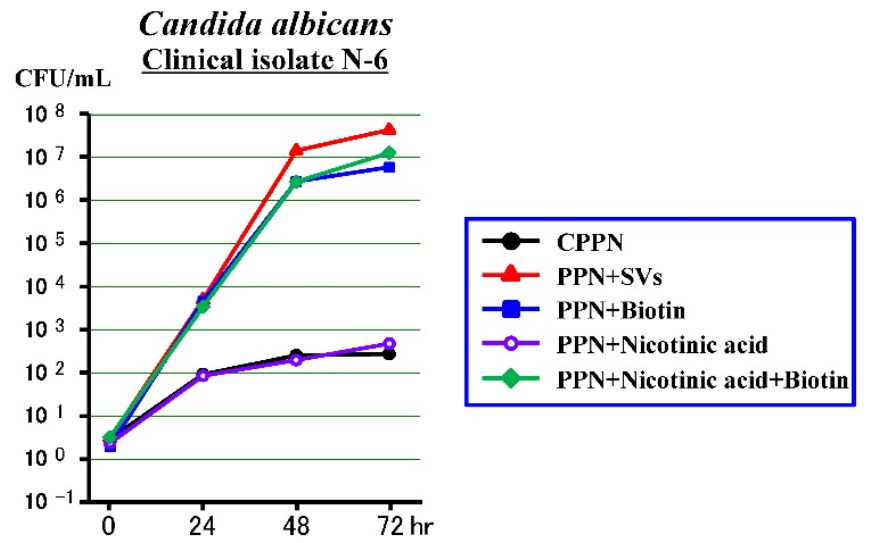

Figure 3. Effects of biotin or nicotinic acid on the growth of Candida albicans in a PPN solution (CPPN).

\section{Discussion}

We have previously shown that bacterial species such as Staphylococcus aureus, Serratia marcescens and Bacillus cereus cannot grow in acidic PN solutions, but Candida albicans can grow rapidly, regardless of acidic $\mathrm{pH}$ values [10, 11]. Furthermore, it has been shown that $C$. albicans can grow equally well in 4 -fold to 7-fold PN solutions hypertonic to physiological saline [12]. Because factors inhibiting Candida growth are unlikely to be determined, the enhancing factors should be investigated and identified. Therefore, we have demonstrated that $C$. albicans needs MVs to increase rapidly in PPN solutions without lipid [18]. In the present study, the effects of vitamins on the growth of C. albicans in PN solutions without lipid were investigated in detail.

First, we examined the growth of $C$. albicans in a PN solution without lipid supplemented with SVs, IVs or both (MVs). The results showed that the SVs equally accelerated the growth of the C. albicans as the MVs, but the IVs did not. Next, to identify which of the vitamins accelerated the growth of the C. albicans, we supplemented the same PN solution with the individual SVs. While the nicotinic acid seemed to have a slight affect, vitamins $B_{1}, B_{2}, B_{6}, B_{12}$ and $C$, and the folic acid and panthenol did not affect the growth of the C. albicans. The biotin accelerated the growth of the C. albicans in a way similar to the SVs. Furthermore, to confirm the growth promoting effect of the biotin, we supplemented a PPN solution with biotin, nicotinic acid and both. In this experiment, it was confirmed that the biotin acted mostly as a promoting factor among the SVs or MVs, but the other vitamins did not.

Biotin is required for cell growth and fatty acid metabolism because it is used as a cofactor for carboxylases, and C. albicans is naturally auxotrophic for biotin [25]. Previous papers have indicated that many strains of $C$. albicans and related species in the genus Candida require biotin for growth [26, 27], and that a few strains or mutants of the other species are auxotrophic for biotin [28-30]. On the other hand, there is one paper which suggested that biotin has no influence on Candida during the first 30 hours of growth [31]. In our results, the promoting effect of biotin was not observed clearly for the first 24 hours; but afterward, the promoting effect of biotin was substantially observed. It was estimated that the biotin stored in the Candida organisms would be available for the first several cycles of cell division, and that the Candida would require biotin thereafter to increase growth.

Although applying the results of this study would be inefficient for total PN solutions containing lipid or/and MVs, it would be efficient for short term PPN solutions without lipid. The PPN solutions commercially available in Japan consist of amino acids, glucose and electrolytes, but do not contain a lipid emulsion and MVs, although some products contain only thiamine (vitamin $B_{1}$ ) for the prevention of Wernicke's encephalopathy or lactic acidosis. In clinical practice, PPN solutions are sometimes supplemented with water-soluble vitamins, such as vitamins $B_{1}, B_{2}, B_{6}, B_{12}$ and $C$, but rarely supplemented with other vitamins or MVs. Recently, blood stream infection (BSI) outbreaks due to Bacillus cereus or Serratia marcescens in patients receiving PPN have been occasionally reported in Japan [32-35], but BSIs due to C. albicans have rarely been reported in PPN patients. Most recently, a PPN product containing 9 water-soluble vitamins including biotin has been released; therefore, BSIs due to $C$. albicans might increase in the future, even in PPN patients.

Taken together, the results of this study suggest that adding MVs or SVs to PN solutions without lipid promotes the growth of $C$. albicans, and this effect is mostly attributable to biotin. Therefore, PPN solutions should be supplemented with the minimum required vitamins for the short term, rather than SVs or MVs.

\section{Abbreviations}

ATCC: American Type Culture Collection; BSI: blood stream infection; CFU: colony forming units; $\mathrm{CPN}$ : the control parenteral nutrition solution without lipid for central venous nutrition (AMINOTRIPA No.1, Otsuka Pharmaceutical Factory, Inc.); CPPN: the control parenteral nutrition solution without lipid for peripheral venous nutrition (AMINOFLUID, Otsuka Pharmaceutical Factory, Inc.); CRBSI: catheter-related blood stream infection; IVs: 4 water-insoluble vitamins (vitamin $\mathrm{A}, \mathrm{D}, \mathrm{E}$ and $\mathrm{K}$ ); MVs: multivitamins containing 9 water-soluble 
vitamins and 4 water-insoluble vitamins; OPR: osmotic pressure ratio to physiological saline; $\mathrm{PN}$ : parenteral nutrition; $\mathrm{PN}+\mathrm{B} 1$ : $\mathrm{CPN}$ supplemented with $0.01 \mathrm{mg} / \mathrm{mL}$ of thiamine hydrochloride; $\mathrm{PN}+\mathrm{B} 2: \mathrm{CPN}$ supplemented with $0.01 \mathrm{mg} / \mathrm{mL}$ of riboflavin sodium phosphate; PN+B6: CPN supplemented with 0.03 $\mathrm{mg} / \mathrm{mL}$ of pyridoxal phosphate; $\mathrm{PN}+\mathrm{B} 12$ : CPN supplemented with $0.5 \mu \mathrm{g} / \mathrm{mL}$ of mecobalamin; PN+Biotin: CPN supplemented with $0.001 \mathrm{mg} / \mathrm{mL}$ of biotin; PN+C: CPN supplemented with $0.1 \mathrm{mg} / \mathrm{mL}$ of ascorbic acid; $\mathrm{PN}+$ Folic acid: $\mathrm{CPN}$ supplemented with $0.015 \mathrm{mg} / \mathrm{mL}$ of folic acid; PN+IVs: one bag $(850 \mathrm{~mL}$, one-half of the daily dose) of CPN supplemented with a daily dose of IVs; PN+MVs: one bag $(850 \mathrm{~mL}$, one-half of the daily dose) of CPN supplemented with a daily dose of MVs; PN+Nicotinic acid: CPN supplemented with $0.04 \mathrm{mg} / \mathrm{mL}$ of nicotinic acid; PN+Panthenol: CPN supplemented with $0.1 \mathrm{mg} / \mathrm{mL}$ of panthenol; PN+SVs: one bag $(850 \mathrm{~mL}$, one-half of the daily dose) of CPN supplemented with a daily dose of SVs; PPN: peripheral parenteral nutrition; PPN+Biotin: CPPN supplemented with $0.001 \mathrm{mg} / \mathrm{mL}$ of biotin; PPN+Nicotinic acid: CPPN supplemented with $0.04 \mathrm{mg} / \mathrm{mL}$ of nicotinic acid; PPN+Nicotinic acid+Biotin: CPPN supplemented with $0.04 \mathrm{mg} / \mathrm{mL}$ of nicotinic acid and $0.001 \mathrm{mg} / \mathrm{mL}$ of biotin; PPN+SVs: $100 \mathrm{~mL}$ of CPPN supplemented with 1/10 of the daily dose of the SVs; SCD: Soybean Casein Digest; SVs: 9 water-soluble vitamins (vitamins $B_{1}, B_{2}$, $\mathrm{B}_{6}, \mathrm{~B}_{12}$ and $\mathrm{C}$, folic acid, nicotinamide, biotin and panthenol); Vit.A IU: international unit for vitamin A.

\section{Acknowledgements}

We thank Masao Ichihara for helpful
suggestions.

\section{Competing Interests}

TK, SK and KS are employees for Otsuka Pharmaceutical Factory, Inc.

\section{References}

1. Banton J. Techniques to prevent central venous catheter infection: products, research, and recommendations. Nutr Clin Pract. 2006; 21: 56-61.

2. Mermel LA, Farr BM, Sherertz RJ, et al. Guidelines for the management of intravascular catheter-related infection. Clin Infect Dis. 2001; 32: 1249-1272

3. Llop J, Badia MB, Comas D, Tubau M, Jodar R. Colonization and bacteremia risk factors in parenteral nutrition catheterization. Clin Nutr. 2001; 20: 527-534.

4. Kruse JA, Shah NJ. Detection and prevention of central venous catheter-related infections. Nutr Clin Pract. 1993; 8: 163-170.

5. Freund HR, Rimon B. Sepsis during total parenteral nutrition. J Parenter Enteral Nutr. 1990; 14: 39-41.

6. Dreesen M, Foulon V, Spriet I, et al. Epidemiology of catheter-related infections in adult patients receiving home parenteral nutrition: A systematic review. Clin Nutr. 2013; 32: 16-26.

7. Rowe CE, Fukuyama TT, Martinoff JT. Growth of microorganisms in total nutrient admixtures. Drug Intell Clin Pharm. 1987; 21: 633-638.

8. Didier ME, Fischer S, Maki DG. Total nutrient admixtures appear safer than lipid emulsion alone as regards microbial contamination: growth properties of microbial pathogens at room temperature. J Parenter Enteral Nutr. 1998; 22: 291-296.
9. Gilbert M, Gallagher SC, Eads M, Elmore MF. Microbial growth patterns in a total parenteral nutrition formulation containing lipid emulsion. J Parenter Enteral Nutr. 1986; 10: 494-497.

10. Kuwahara T, Kaneda S, Shimono K, Inoue Y. Growth of microorganisms in total parenteral nutrition solutions without lipid. Int J Med Sci. 2010; 7: 43-47.

11. Kuwahara T, Shimono K, Kaneda S, Tamura T, Ichihara M, Nakashima Y. Growth of microorganisms in total parenteral nutrition solutions containing lipid. Int J Med Sci. 2010; 7: 101-109.

12. Ishida K, Nakao S, Sata T, et al. Fungistatic action of the total parenteral nutrition (TPN) fluids against clinically isolated Candida albicans [in Japanese]. Jpn J Pharm Health Care Sci. 2002; 28: 259-262.

13. Brosh-Nissimov T, Ben-Ami R. Differential association of fluconazole dose and dose/MIC ratio with mortality in patients with Candida albicans and non-albicans bloodstream infection. Clin Microbiol Infect. 2015; 21: 1011-1017.

14. Bassetti M, Merelli M, Ansaldi F, et al. Clinical and therapeutic aspects of Candidemia: a five year single centre study. PLoS One. 2015; 10: e0127534.

15. Girao E, Levin AS, Basso M, et al. Seven-year trend analysis of nosocomial candidemia and antifungal (fluconazole and caspofungin) use in intensive care units at a Brazilian university hospital. Med Mycol. 2008; 46: 581-588.

16. Wisplinghoff $\mathrm{H}$, Bischoff $\mathrm{T}$, Tallent SM, Seifert H, Wenzel RP, Edmond MB. Nosocomial bloodstream infections in US hospitals analysis of 24,179 cases from a prospective nationwide surveillance study. Clin Infect Dis. 2004; 39: 309-317.

17. Nielsen H, Stenderup J, Bruun B. Fungemia in a university hospital 1984-1988: clinical and mycological characteristics. Scand J Infect Dis. 1991; 23: 275-282.

18. Kuwahara T, Kaneda S, Shimono K, Inoue Y. Effects of lipid emulsion and multivitamins on the growth of microorganisms in peripheral parenteral nutrition solutions. Int J Med Sci. 2013; 10: 1079-1084.

19. Kuwahara T, Kaneda S, Shimono K, Tamura T, Nakashima Y. Adding multivitamins to parenteral nutrition solutions promotes the growth of Candida albicans. Clin Nutr Suppl. 2008; 3 (suppl 1): 172-173.

20. The Japanese Pharmacopoeia, Sixteenth Edition. Ministry of Health, Labor and Welfare. Tokyo, 2011.

21. Jarvis WR, Highsmith AK. Bacterial growth and endotoxin production in lipid emulsion. J Clin Microbiol. 1984; 19: 17-20

22. Keammerer D, Mayhall CG, Hall GO, Pesko LJ, Thomas RB. Microbial growth patterns in intravenous fat emulsions. Am J Hosp Pharm. 1983; 40: 1650-1653.

23. Murano A, Morinaga N, Iwamaru $\mathrm{Y}$, et al. Acidic conditions enhance bactericidal effects of sodium bisulfite on Helicobacter pylori. Helicobacter. 2005; 10: 132-135.

24. Obayashi A, Oie S, Kamiya A. Microbial viability in preparations packaged for single use. Biol Pharm Bull. 2003; 26: 667-670.

25. Hasim S, Tati S, Madayiputhiya N, Nandakumar R, Nickerson KW. Histone biotinylation in Candida albicans. FEMS Yeast Res. 2013; 13: 529-539.

26. Miyashita S. Studies on the nutrition of Candida - 1. Nutritional requirements of Candida. [in Japanese] Jpn J Bacteriol. 1956; 11: 907-910.

27. Firestone BY, Koser SA. Growth promoting effect of some biotin analogues for Candida albicans. J Bacteriol. 1960; 79: 674-676.

28. Summers JW, Wyss O. Biotin-deficient growth of Bacillus polymyxa. J Bacteriol. 1967; 94: 1908-1914.

29. Bowman W, DeMoll E. Biosynthesis of biotin from dethiobiotin by the biotin auxotroph Lactobacillus plantarum. J Bacteriol. 1993; 175: 7702-7704.

30. Magliano P, Flipphi M, Arpat BA, Delessert S, Poirier Y. Contributions of the peroxisome and B-oxidation cycle to biotin synthesis in fungi. J Biol Chem. 2011; 286: 42133-42140.

31. Vidotto V, Pugliese A, Gioannini P. Growth of Candida albicans in a minimal synthetic medium without biotin. Mycopathologia. 1987; 100: 7-15.

32. Sasahara T, Hayashi S, Morisawa Y, Sakihama T, Yoshimura A, Hirai $Y$. Bacillus cereus bacteremia outbreak due to contaminated hospital linens. Eur J Clin Microbiol Infect Dis. 2011; 30: 219-226.

33. Aso Y, Nagatomi M, Nakazawa T, Sakaki S, Ishi K. Examination of infection fluid type and environmental factors involved in increased Bacillus cereus bloodstream infection [in Japanese]. Jpn J Environ Infect. 2012; 27: 81-90

34. Matsumoto S, Suenaga H, Naito K, Sawazaki M, Hiramatsu T, Agata N. Management of suspected nosocomial infection: an adult of 19 hospitalized patients with septicemia caused by Bacillus species. Jpn J Infect Dis. 2000; 53: 196-202

35. Iwaya A, Nakagawa S, Taneike I, et al. Serratia infection and sanitary management of fluid administration [in Japanese]. Niigata-igakukai-zasshi. 2003; 117: 469-478. 